\title{
The Unexplainable Nature of Momentum Portfolio Returns
}

\author{
David J. Moore1, George C. Philippatos ${ }^{2}$ \\ ${ }^{1}$ College of Business, Administration, California State University, Sacramento, USA \\ ${ }^{2}$ Department of Finance, University of Tennessee, Knoxville, USA \\ Email: djmphd@csus.edu, gcphilipp1@gmail.com
}

Received 21 January 2014; revised 6 March 2014; accepted 31 March 2014

Copyright (C) 2014 by authors and Scientific Research Publishing Inc.

This work is licensed under the Creative Commons Attribution International License (CC BY).

http://creativecommons.org/licenses/by/4.0/

(c) (i) Open Access

\begin{abstract}
We find that momentum portfolio returns are still unexplainable after addressing two major concerns in the "Investment Manifesto" of Lin and Zhang [1]: lack of economic basis in risk factor models and aggregate data measurement error. Our model represents a synthesis of the exchange economy model of Lucas and closed economy exogenous growth model of King and Rebelo. We mitigate data measurement error by utilizing firm-level financial data and production functions rather than macroeconomic data and utility functions. Although our results fail to completely explain momentum, they are consistent with the "Investment Manifesto" suggestion that firm-level market-to-book and productivity are important factors in describing returns.
\end{abstract}

\section{Keywords}

Momentum, Productivity, Macroeconomic, CAPM, Asset Pricing

\section{Introduction}

The "Investment Manifesto" of Lin and Zhang [1] attributes the inability to explain anomalies such as momentum to a lack of economic basis in characteristic-based linear factor models and the inability to identify and accurately measure aggregate factors that affect all asset returns simultaneously. We agree with Lin and Zhang [1] that using returns to explain returns, e.g., the Carhart [2] winners minus losers (WML) factor to explain momentum or Fama and French [3] small minus big (SMB) and high minus low book-to-market (HML) to explain size and distress anomalies, is an "atheoretical, ad hoc, and mechanical approach".

One could argue that the market risk premium (MRP) of the capital asset pricing model (CAPM) is an identifiable and measurable proxy for aggregate market risk. However, the static CAPM is unable to explain many anomalies such as the size premium, distress premium, and momentum. This is largely due to necessarily time varying CAPM coefficients. Cochrane [4] shows that the derivation of the CAPM and connection to 
discount factor models imply time-varying coefficients. Intuitively, a firm's exposure to market risk can and will change over time due to changes in leverage, product mix, etc.

Lewellen and Nagel [5] argue that conditional CAPM models can not explain momentum for two reasons. First, the authors directly estimate conditional betas and find their variation too small to explain pricing errors. Second, from a theoretical perspective, the econometrician must know the "right" state variables that cause time varying coefficients. As such, conditional linear factor models are not testable since they are conditioned on observable values rather than the investors' information sets [4].

In this paper we make an attempt to address the lack of economic basis and measurement error concerns of Lin and Zhang [1]. Our model represents a synthesis of the exchange economy model of Lucas and the closed economy exogenous growth model of King and Rebelo [6]. We derive an aggregate productivity (the ratio of aggregate production to aggregate capital) based marginal utility growth function from the first order conditions of the growth model. The new productivity based proxy overcomes the practical difficulties in utility function specification and low time variability of consumption data. Furthermore, we aggregate firm-level financial data from Compustat to mitigate measurement error associated with traditional macroeconomic time series.

Although our regression of momentum portfolio returns on our new productivity measure produces significant alphas, all betas in our model are significant. Furthermore, all HML betas are also significant in unconditional estimation of the momentum returns on the Fama-French three-factor model. The significant productivity and HML betas are consistent with the investment return equation of Lin and Zhang [1] that is based on firm-level productivity and market-to-book ratio. We believe these results support continued research focusing on the impact of firm-level productivity and market-to-book ratios on market returns.

\section{Theoretical Foundations}

\subsection{Exchange Economy Model}

The exchange economy model of Lucas [7] yields the Euler condition for a representative agent's intertemporal utility maximization:

$$
p_{t} u^{\prime}\left[c_{t}\right]=\beta E_{t}\left[u^{\prime}\left[c_{t+1}\right]\left(p_{t+1}+d_{t+1}\right)\right]
$$

where $E_{t}$ is the time $t$ expectations operator, $p_{t}$ is the price at time $t, c_{t}$ is the consumption at time $t$, $\beta$ is the rate of time preference (subjective discount factor), and $d_{t+1}$ are dividends paid at time $t+1$. The equality in (1) reveals that the cost in marginal utility $\left(p_{t} u^{\prime}\left[c_{t}\right]\right)$ of purchasing the asset must be equal to the discounted $(\beta)$ expected gain of the future payoff $\left(u^{\prime}\left[c_{t+1}\right]\left(p_{t+1}+d_{t+1}\right)\right)$. By dividing both sides by $p_{t} u^{\prime}\left[c_{t}\right]$ and defining $R_{t+1} \equiv\left(p_{t+1}+d_{t+1}\right) / p_{t}$ Equation (1) can be expressed in discount factor form:

$$
E_{t}\left[m_{t+1} R_{t+1}\right]=1
$$

where

$$
m_{t+1}=\beta \frac{u^{\prime}\left[c_{t+1}\right]}{u^{\prime}\left[c_{t}\right]}
$$

Marginal utility growth $\left(u^{\prime}\left[c_{t+1}\right] / u^{\prime}\left[c_{t}\right]\right)$ in the stochastic discount factor Equation (3) is unobservable. In the next section, we derive an aggregate productivity based marginal utility growth function from the first order conditions of an economic growth model. That measurable proxy for marginal utility growth shall be substituted into Equation (2) and then tested empirically.

\subsection{Macroeconomic Growth Model}

The relationship between marginal utility growth and asset prices is represented by Equation (2). Given the unobservable nature of utility, obtaining a correct utility functional form is elusive. In this section, a discrete time general equilibrium macroeconomic growth model based on that of King and Rebelo [6] is employed to arrive at an alternative function for marginal utility growth. This productivity-based function is utilized in subsequent asset pricing tests as a substitute for marginal utility growth. This substitution bypasses the difficulty in specifying a utility function and low variability of consumption data. 


\subsubsection{Choice of General Equilibrium Model}

We use a general equilibrium (central planner) approach for several reasons. First, general equilibrium models allow both supply (firm) and demand (shareholder) interactions while partial equilibrium models treat one side as exogenous. For instance, macroeconomic theory and intuition suggest an increase in productivity (supply side), even if only temporary, impacts consumption (demand side). Second, Abel and Blanchard ([8], p. 683), who prove the equivalence of a central planner vs. market economy approach, state the general equilibrium (central planner) approach is

“...very useful as it allows, when studying the effects of various shocks or policies, to use the equations of motion of the centralized economy with its unique shadow price rather than the equations of motion of the market economy with two shadow prices which themselves depend on market-determined interest rates."

Therefore the complexities associated with the inclusion of market-determined interest rates, which are beyond the scope of this study, are bypassed in the central planner approach. Again, the goal here is to establish a connection between marginal utility growth and productivity.

\subsubsection{The Model}

The model developed here follows the exogenous growth model of King and Rebelo [6]. Exogenous growth is introduced via labor augmentation consistent with Sala-i Martin ([9], p. 32) who states:

“...as Phelps showed, a necessary and sufficient condition for the existence of a steady state in an economy with exogenous technological progress is for this technological progress to be Harrod Neutral or Labor Augmenting"

As such, we specify the production function in Cobb-Douglas form:

$$
Y_{t}=A_{t} F\left[K_{t}, N_{t} X_{t}\right]=A_{t} K_{t}^{1-\alpha}\left(N_{t} X_{t}\right)^{\alpha}
$$

where $Y_{t}$ represents output, $K_{t}$ capital input, $N_{t}$ labor input, $A_{t}$ the random productivity shock, and $X_{t}$ the deterministic component of productivity which grows at a constant (and exogenous) rate $\gamma>1: X_{t+1}=\gamma X_{t}$.

We chose the Cobb-Douglas production function for several reasons. First, by construction this production function exhibits constant returns to scale, consistent with the empirical findings of Jorgenson [10]. Therefore it is not subject to the scale or non-decreasing returns effects associated with endogenous growth formulations and allows for equivalence between marginal $q$ and average $q$ [11]. Second, the empirical evidence noted by Jorgenson [10] suggests the estimated elasticity of substitution for the CES production function is not significantly different from unity and therefore the CES reduces to Cobb-Douglas form. Third, Arroyo [12] suggests the CobbDouglas form is "probably more descriptive of aggregate technological conditions".

\subsubsection{Maximization Problem}

The infinitely-lived central planner maximizes discounted expected utility

$$
E_{0}\left\{\sum_{t=0}^{\infty} b^{t} u\left[C_{t}\right]\right\}
$$

where $b^{t}<0$ represents the rate of time preference, subject to several constraints. To begin, all output is either consumed or invested in this closed economy with no government presence:

$$
Y_{t}=C_{t}+I_{t}
$$

In addition, capital stock evolves according to the "perpetual inventory method":

$$
K_{t+1}=I_{t}+(1-\delta) K_{t}
$$

where $\delta$ represents the rate of depreciation. All variables are expressed in per-capita (population) terms. Labor market and wages are not the focus of this study therefore the labor input is normalized to $1\left(N_{t}=1 \forall t\right)$.

A central planner with choice variables of consumption $C_{t}$ and investment (via the choice of next period's capital $K_{t+1}$ ) is faced with the maximization problem:

$$
\max _{C_{t}, K_{t+1}} \sum_{t=0}^{\infty} b^{t} u\left[C_{t}\right] \quad \text { subject to }
$$




$$
K_{t+1}=A_{t} K_{t}^{1-\alpha}\left(N_{t} X_{t}\right)^{\alpha}+(1-\delta) K_{t}-C_{t}
$$

where Equation (8) is obtained by combining Equations. (4), (5), and (6). The Lagrangian is:

$$
\mathcal{L}=\sum_{t=0}^{\infty} b^{t} u\left[C_{t}\right]+\sum_{t=0}^{\infty} b^{t} \lambda_{t}\left(A_{t} K_{t}^{1-\alpha} X_{t}^{\alpha}+(1-\delta) K_{t}-C_{t}-K_{t+1}\right)
$$

\subsubsection{Solution}

The first order conditions are:

$$
\begin{gathered}
\frac{\partial \mathcal{L}}{\partial C_{t}}=b^{t} u^{\prime}\left[C_{t}\right]-b^{t} \lambda_{t}=0 \Rightarrow u^{\prime}\left[C_{t}\right]=\lambda_{t} \\
\frac{\partial \mathcal{L}}{\partial K_{t+1}}=b^{t+1} \lambda_{t+1}\left((1-\alpha) A_{t+1} K_{t+1}^{-\alpha} X_{t}^{\alpha}+(1-\delta)\right)-b^{t} \lambda_{t}=0
\end{gathered}
$$

We note that $Y_{t+1} / K_{t+1}=A_{t+1} K_{t+1}^{-\alpha} X_{t}^{\alpha}$ and abstract away from explicit specification of random $\left(A_{t+1}\right)$ and deterministic $\left(X_{t+1}\right)$ components of productivity. As such, Equation (11) simplifies to:

$$
b^{t+1} \lambda_{t+1}\left((1-\alpha)\left(Y_{t+1} / K_{t+1}\right)+(1-\delta)\right)-b^{t} \lambda_{t}=0
$$

Equations (10) and (12) are combined to reveal an alternative proxy for marginal utility growth:

$$
\frac{u^{\prime}\left[C_{t+1}\right]}{u^{\prime}\left[C_{t}\right]}=\frac{1}{b\left((1-\alpha)\left(Y_{t+1} / K_{t+1}\right)+(1-\delta)\right)}
$$

Equation (13) provides a convenient and readily observable proxy for unobservable marginal utility growth. This function serves as a direct replacement for marginal utility growth in the Euler condition Equation (2). The first order approximation of Equation (13) provides a linear discount factor for use in linear regression:

$$
m_{t+1}=a_{0}+a_{1} P R O D_{t+1}
$$

where $P R O D_{t}=Y_{t} / K_{t}$ is the time-varying productivity from Equation (13).

Cochrane [4] notes that discount factor models $E\left[m_{t+1} R_{t+1}\right]-1=0$ lead to time series regressions:

$$
R_{t}=\alpha+\beta P R O D_{t}+\epsilon_{t}
$$

and we use this functional form later in subsequent empirical specifications.

In sum, the exchange economy of Lucas produces the Euler condition in Equation (2). The first order conditions of the macroeconomic growth model yield the productivity based marginal utility growth discount factor in Equation (13). Substitution of the linear approximation of this new discount factor into the Euler condition represents the synthesis of the exchange economy and macroeconomic growth models.

\subsection{Lin and Zhang Two Period Model Comparison}

Lin and Zhang [1] employ a two period general equilibrium model with adjustment costs and arrive at a function equating stock $\left(R_{i 1}^{S}\right)$ and investment $\left(R_{i 1}^{I}\right)$ return:

$$
R_{i 1}^{S}=\frac{\Pi_{i 1}}{1+a\left(I_{i 0} / K_{i 0}\right)}=R_{i 1}^{I}
$$

where $\Pi_{i 1}$ is the productivity of firm $i$ in period $1, I_{i 0}$ is the investment by firm $i$ in period $0, K_{i 0}$ is the capital for firm $i$ in period 0 , and $a$ is an adjustment cost constant. The authors define operating cash flow as $\Pi_{i t} K_{i t}$ therefore productivity $\Pi_{i 1}=O C F_{i 1} / K_{i 1}$ where $O C F_{i 1}$ is operating cash flow of firm $i$ in period 1. The authors note the denominator in Equation (16) is nothing more than market-to-book. Therefore, market returns at time 1 are related to productivity during period 1 and the market-to-book ratio at time 0 (the time of purchase).

Equation (16) does not explicitly relate any aggregate factors to firm returns. Lin and Zhang [1] borrow from 
Brock [13] to incorporate aggregate factors $\tilde{X}_{t}^{f}$ and firm-specific loadings $L_{i t}^{f}$ on those factors into their stock return equation:

$$
R_{i 1}^{S}=\sum_{f=1}^{F} \frac{L_{i 1}^{f} \tilde{X}_{1}^{f}}{1+a\left(I_{i 0} / K_{i 0}\right)}
$$

The implementation difficulty is in identifying and accurately measuring the relevant aggregate risk factors $\tilde{X}_{t}^{f}$ that affect all firms in the economy. Examples of risk factors include aggregate productivity shocks, changes in government policy, war, and recessions. In this study our proxy for aggregate productivity includes shocks to productivity by construction. Our model does not include market-to-book ratios. However, we investigate market-to-book influences via loadings on the high minus low book-to-market factor in Fama-French three-factor model regressions.

\section{Data and Methodology}

\subsection{Data Sources}

Table 1 summarizes the sources, frequency, and sample window of the data used in this study and Table 2 presents brief summary statistics. Sections 3.2 and 3.3 present more detail on momentum return and productivity time series data, respectively. Aggregate macroeconomic data are constructed by summing Compustat quarterly firm-level sales data to obtain output $Y$ and net property plant and equipment to obtain capital $K$. We chose to aggregate firm-level financial data over downloading Bureau of Economic Analysis (BEA) macroeconomic data to mitigate measurement error referenced by Lin and Zhang [1]. Equity return data are obtained form the Kenneth French website and fixed income returns are obtained from the Federal Reserve Bank H.15 reports.

\subsection{Momentum Evidence}

Following Fama and French [14], this study analyzes momentum portfolios with a 12-month formation period and one month holding period. Momentum return data are obtained from the Kenneth R. French website. We present mean daily returns for prior-return portfolios over several sample periods in Table 3 . There are several observations of note. Mean daily returns generally increase monotonically with prior 12-month performance with the exception of 2000-2012 (Column V). The 2000s, of course, are characterized by several unique events such as the dot com bust of 2000, the 2001 terrorist attacks, the financial market meltdown, and various sovereign debt crises. These adverse events had a significant impact on all stock returns and consequently momentum portfolio returns.

Table 1. Data items, sources, and sample window.

\begin{tabular}{|c|c|c|c|}
\hline Item & Var & Frequency & Sample window \\
\hline Output (SALEQ) & $Y$ & Quarterly & 1962 Q1-2012 Q4 \\
\hline Capital (PPENTQ) & $K$ & Quarterly & 1962 Q1-2012 Q4 \\
\hline Excess market index returns & $M R P$ & Daily & 19270101-20121231 \\
\hline Small minus big size returns & $S M B$ & Daily & 19270101-20121231 \\
\hline High minus low book-to-market returns & $H M L$ & Daily & 19270101-20121231 \\
\hline 10 prior-return portfolios & $M x x$ & Daily & 19270101-20121231 \\
\hline 12 industry portfolios & $I N D x$ & Daily & 19270101-20121231 \\
\hline One-month T-Bill rate & $R_{f}$ & Daily & 19270101-20121231 \\
\hline \multirow[t]{2}{*}{ Long term (10-year) gov’t bond } & \multirow[t]{2}{*}{$R_{f 10 y}$} & Monthly & 196201-201212 \\
\hline & & Daily & 19620102-20121231 \\
\hline \multirow[t]{2}{*}{ High grade corporate bond } & \multirow[t]{2}{*}{$R_{\text {aaa }}$} & Monthly & $196201-201212$ \\
\hline & & Daily & 19830103-20121231 \\
\hline \multirow[t]{2}{*}{ Low grade corporate bond } & \multirow[t]{2}{*}{$R_{b a a}$} & Monthly & 196201-201212 \\
\hline & & Daily & $19860102-20121231$ \\
\hline
\end{tabular}


Table 2. Input data summary statistics.

\begin{tabular}{|c|c|c|c|c|c|c|c|c|c|c|c|c|}
\hline \multicolumn{13}{|c|}{ Fama-French Factors } \\
\hline & MRP & SMB & HML & $R_{f}$ & & & & & & & & \\
\hline mean & 0.0207 & 0.0040 & 0.0118 & 0.0087 & & & & & & & & \\
\hline stdev & 0.1123 & 0.0585 & 0.0673 & 0.0076 & & & & & & & & \\
\hline $\mathrm{N}$ & 348 & 348 & 348 & 348 & & & & & & & & \\
\hline \multicolumn{13}{|c|}{ Gross industry portfolio returns } \\
\hline INDxx & 01 & 02 & 03 & 04 & 05 & 06 & 07 & 08 & 09 & 10 & 11 & 12 \\
\hline mean & 0.0307 & 0.0365 & 0.0331 & 0.0326 & 0.0329 & 0.0350 & 0.0266 & 0.0278 & 0.0314 & 0.0334 & 0.0322 & 0.0275 \\
\hline stdev & 0.0955 & 0.1764 & 0.1444 & 0.1071 & 0.1210 & 0.1532 & 0.0926 & 0.1141 & 0.1211 & 0.1118 & 0.1480 & 0.1456 \\
\hline $\mathrm{N}$ & 346 & 346 & 346 & 346 & 346 & 346 & 346 & 346 & 346 & 346 & 346 & 346 \\
\hline \multicolumn{13}{|c|}{ Gross momentum portfolio returns } \\
\hline MOMxx & 01 & 02 & 03 & 04 & 05 & 06 & 07 & 08 & 09 & 10 & & \\
\hline mean & 0.0195 & 0.0281 & 0.0286 & 0.0278 & 0.0277 & 0.0294 & 0.0302 & 0.0364 & 0.0362 & 0.0452 & & \\
\hline stdev & 0.2172 & 0.1914 & 0.1441 & 0.1305 & 0.1257 & 0.1148 & 0.1169 & 0.1106 & 0.1181 & 0.1351 & & \\
\hline $\mathrm{N}$ & 345 & 345 & 345 & 345 & 345 & 345 & 345 & 345 & 345 & 345 & & \\
\hline \multicolumn{13}{|c|}{ Federal Reserve Board H.15 data } \\
\hline & $R_{f 10 y}$ & $R_{\text {aaa }}$ & $R_{\text {bаa }}$ & & & & & & & & & \\
\hline mean & 0.0164 & 0.0187 & 0.0213 & & & & & & & & & \\
\hline stdev & 0.0068 & 0.0063 & 0.0069 & & & & & & & & & \\
\hline $\mathrm{N}$ & 210 & 210 & 210 & & & & & & & & & \\
\hline
\end{tabular}

Table 3. Mean daily gross returns.

\begin{tabular}{|c|c|c|c|c|c|c|}
\hline & I & II & III & IV & $\mathrm{V}$ & VI \\
\hline Begin & 19610131 & 19700101 & 19800101 & 19900101 & 20000101 & 19610131 \\
\hline End & 19691231 & 19791231 & 19891231 & 19991231 & 20121231 & 20121231 \\
\hline \multirow[t]{2}{*}{ M01 } & 0.0122 & -0.0148 & 0.0202 & 0.0246 & 0.0020 & 0.0084 \\
\hline & 0.5757 & 0.6685 & 0.4523 & 0.3906 & 0.9666 & 0.5964 \\
\hline \multirow[t]{2}{*}{ M02 } & 0.0110 & 0.0089 & 0.0594 & 0.0422 & 0.0299 & 0.0307 \\
\hline & 0.5493 & 0.7576 & 0.0086 & 0.0721 & 0.3878 & 0.0121 \\
\hline \multirow[t]{2}{*}{ M03 } & 0.0281 & 0.0212 & 0.0715 & 0.0564 & 0.0257 & 0.0400 \\
\hline & 0.1082 & 0.3909 & 0.0006 & 0.0047 & 0.3677 & 0.0001 \\
\hline \multirow[t]{2}{*}{ M04 } & 0.0195 & 0.0297 & 0.0662 & 0.0538 & 0.0327 & 0.0404 \\
\hline & 0.2320 & 0.2171 & 0.0014 & 0.0033 & 0.1852 & 0.0000 \\
\hline \multirow[t]{2}{*}{ M05 } & 0.0317 & 0.0196 & 0.0609 & 0.0502 & 0.0312 & 0.0384 \\
\hline & 0.0461 & 0.3872 & 0.0032 & 0.0038 & 0.1652 & 0.0000 \\
\hline \multirow[t]{2}{*}{ M06 } & 0.0305 & 0.0347 & 0.0588 & 0.0588 & 0.0321 & 0.0427 \\
\hline & 0.0683 & 0.1167 & 0.0049 & 0.0007 & 0.1200 & 0.0000 \\
\hline \multirow[t]{2}{*}{ M07 } & 0.0317 & 0.0243 & 0.0681 & 0.0657 & 0.0205 & 0.0411 \\
\hline & 0.0641 & 0.2663 & 0.0017 & 0.0001 & 0.3137 & 0.0000 \\
\hline \multirow[t]{2}{*}{ M08 } & 0.0454 & 0.0376 & 0.0787 & 0.0712 & 0.0363 & 0.0530 \\
\hline & 0.0131 & 0.0774 & 0.0003 & 0.0000 & 0.0793 & 0.0000 \\
\hline \multirow[t]{2}{*}{ M09 } & 0.0474 & 0.0423 & 0.0701 & 0.0701 & 0.0199 & 0.0483 \\
\hline & 0.0185 & 0.0650 & 0.0032 & 0.0003 & 0.3684 & 0.0000 \\
\hline \multirow[t]{2}{*}{ M10 } & 0.0843 & 0.0599 & 0.0761 & 0.1057 & 0.0319 & 0.0690 \\
\hline & 0.0013 & 0.0227 & 0.0064 & 0.0000 & 0.2796 & 0.0000 \\
\hline \multirow[t]{2}{*}{ UMD } & 0.0721 & 0.0747 & 0.0559 & 0.0811 & 0.0299 & 0.0606 \\
\hline & 0.0004 & 0.0025 & 0.0133 & 0.0008 & 0.4749 & 0.0000 \\
\hline
\end{tabular}


The portfolio long on the best performing stocks (M10) and short the worst performing stocks (M01), UMD, is positive and significant for the entire sample (January 31, 1961 to December 31, 2012) and all subsamples except the January 1, 2000 to December 31, 2012 subsample (Column V). Looking to Column VI, mean daily returns increase approximately monotonically with prior 12-month performance. These univariate results are qualitatively similar to those of Chordia and Shivakumar [15]. We now have a suitable set of test assets for our momentum analysis.

Table 1 reports sources for data used in this study. Quarterly output and capital data are derived from Compustat quarterly firm-level data. Daily equity return data are obtained from the Kenneth French website. Market index excess returns $M R P$, prior return portfolio returns $M x x$, and 12 industry portfolio returns $I N D x$ are based on value-weighted portfolios. Gross momentum and industry portfolio returns are converted to excess returns by subtracting the one-month T-bill rate $R_{f}$. Long-term government $\left(R_{f 10 y}\right)$, high grade corporate $\left(R_{\text {aaa }}\right)$, and low grade corporate $\left(R_{\text {baa }}\right)$ bond data are obtain from the Federal Reserve Bank H.15 reports.

Table 2 reports summary statistics for input data. Reported values are based on quarterly data. Quarterly Fama-French factor, industry portfolio, and momentum portfolio returns are obtained by aggregating daily data. Quarterly Federal Reserve Board H.15 data are obtained by taking the quarterly mean of monthly data.

Table 3 reports mean daily gross returns expressed as percentage for value-weighted price momentum portfolios. Results are tabulated for sub-samples (Columns I through V) and the entire sample (Column VI). Portfolios are formed at the end of month $t-1$ and sorted into deciles (M01 through M10) based on ascending prior 12-month returns. In addition, mean returns are reported for a portfolio (UMD) long on the highest prior return decile (M10) and short on the lowest prior return decile (M01). All portfolios are held for one month after formation period. $p$-values for all estimates are in italics. $p$-values are based on Andrews [16] heteroskedasticity and autocorrelation consistent (HAC) covariance matrices. Significance at the $5 \%$ level or better is indicated by bold estimates.

Aggregate firm-level financial data from Compustat over the 1962 Q1 to 2012 Q4 time period. Quarterly aggregate output $Y$ is the sum of quarterly firm-level sales. Quarterly aggregate capital $K$ is the sum of quarterly firm-level net property plant and equipment.

\subsection{Productivity Time Series}

We approach the macroeconomic data measurement error in a new way. Rather than use the traditional BEA macroeconomic data, we construct our own macroeconomic variables by aggregating firm-level data from Compustat. The Compustat dataset has 628,144 firm-quarter observations of NYSE, AMEX, and NASDAQ listed stocks over the 1962 Q1 to 2012 Q4 time period. The firm-quarter observations are aggregated by calendar quarter by summation with 3049 firms per quarter on average. The resulting aggregate sales and net property, plant, and equipment (net PP\&E) are treated as aggregate output $Y$ and capital $K$, respectively. The association of sales with output and PP\&E as capital is straightforward. Note that we choose net PP\&E over gross PP\&E for consistency with depreciated capital $K$ in Equation (6) of the macroeconomic growth model.

We note a possible relation between productivity and momentum profitability when looking at Table 3 and Figure 1. Momentum profitability is higher in decades where productivity has increased. In the 1970s, the average UMD return of $0.0747 \%$ (Table 3, Column II) is higher than the full sample average of $0.0606 \%$ (Table 3 , Column VI) and coincident with a rise in productivity. In the 1980s, the average UMD return of $0.0559 \%$ (Table 3, Column III) is below the full sample average and coincident with relatively flat productivity. In the 1990s the average UMD return of $0.0811 \%$ is higher than the full sample average and coincident with significant productivity gains. Finally, in the volatile 2000s, the average UMD return of $0.0299 \%$ is below the full sample average, statistically insignificant, and coincident with a decline in productivity. In sum, we have anecdotal evidence that non-declining productivity is coincident with higher momentum profitability.

Table 4 reports results for the regression:

$$
P R O D_{t}=\sum_{i=1}^{16} \beta_{i} R_{i t}+\epsilon_{t}
$$

where $P R O D_{t}$ is the (mean adjusted) productivity time series, $\beta_{i}$ is the weight associated with portfolio $i$, 


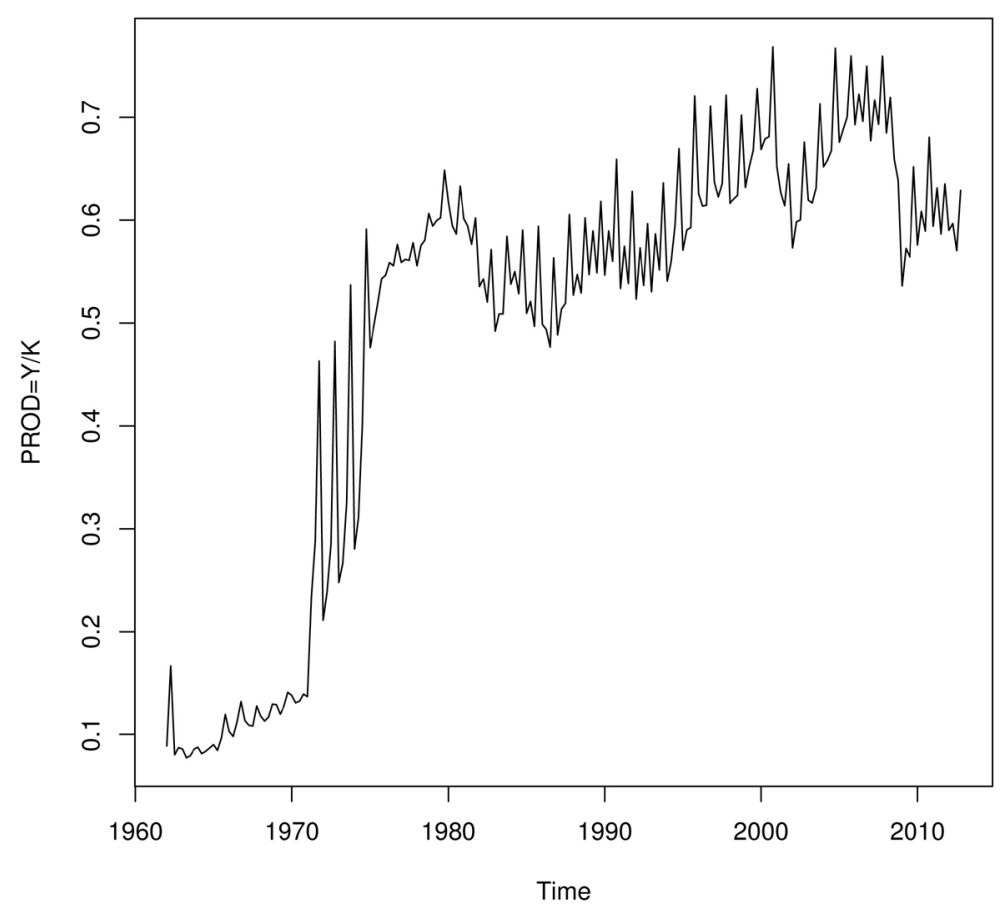

Figure 1. Quarterly productivity time series.

Table 4. Factor-mimicking portfolio regression results.

\begin{tabular}{|c|c|c|c|c|}
\hline$i$ & Symbol & Description & $\beta_{i}$ & $p$-value \\
\hline 1 & IND01 & Non-durables & $-0.1985^{+}$ & 0.0849 \\
\hline 2 & IND02 & Durables & 0.0879 & 0.1386 \\
\hline 3 & IND03 & Manufacturing & -0.0975 & 0.4668 \\
\hline 4 & IND04 & Energy & 0.0618 & 0.3148 \\
\hline 5 & IND05 & Chemicals & 0.0747 & 0.3827 \\
\hline 6 & IND06 & Business equipment & 0.0714 & 0.4739 \\
\hline 7 & IND07 & Telecommunications & -0.0002 & 0.9978 \\
\hline 8 & IND08 & Utilities & -0.0162 & 0.7550 \\
\hline 9 & IND09 & Shops (retail) & $0.1260^{+}$ & 0.0954 \\
\hline 10 & $I N D 10$ & Healthcare & $0.1630^{*}$ & 0.0271 \\
\hline 11 & IND11 & Financials & 0.0346 & 0.7755 \\
\hline 12 & IND12 & Other & $0.1851^{+}$ & 0.0790 \\
\hline 13 & $R_{f 10 y}$ & Long term government & 11.0590 & 0.0001 \\
\hline 14 & $R_{\text {aаa }}$ & High grade corporate & $-15.1050^{* *}$ & 0.0050 \\
\hline 15 & $R_{b a a}$ & Low grade corporate & 5.1212 & 0.1366 \\
\hline 16 & $M R P$ & CRSP value-weighted portfolio & -0.5673 & 0.1520 \\
\hline
\end{tabular}

and $R_{\text {it }}$ are the excess returns of 12 industry portfolios, 3 bond portfolios, and the CRSP value-weighted market index. The regression F-statistic is 2.55 with a $p$-value of 0.0014 and adjusted $R^{2}$ of 0.178 . Significance based on $t$-tests at the $10 \%, 5 \%, 1 \%$, and $0.1 \%$ levels are indicated by “+”, “*”, “**”, and “***”, respectively. The sample includes data from 1962 Q1 to 2012 Q4.

\subsection{Daily Productivity Series Estimation}

Compustat company financial data is lower frequency (quarterly) than momentum return data (daily). Given 
greater statistical power associated with more observations (higher frequency data) we convert the quarterly Compustat data to daily by employing the factor-mimicking-portfolio approach of Breeden et al. [17] and Cochrane [4]. The factor-mimicking approach captures the portion of PROD correlated with the test excess returns via a zero-intercept linear regression ([4], p. 16). We form a set of quarterly excess returns of twelve industry portfolios (using the Fama-French 12-industry designations), three bond portfolios (long term government, high grade corporate, and low grade corporate), and the CRSP value-weighted portfolio. The sample includes 204 quarterly observations from 1962Q1 to 2012Q4. Next we perform the regression

$$
\operatorname{PROD}_{t}=\sum_{i=1}^{16} \beta_{i} R_{i t}+\epsilon_{t}
$$

where $P R O D_{t}$ is the (mean adjusted) productivity time series, $R_{i t}$ are the excess returns of the set of 16 assets in Table 4, and $\beta_{i}$ is the weight associated with portfolio $i$. Elimination of the intercept allows us to capture the portion of our factor-mimicking portfolio that is correlated with the productivity time series $P R O D_{t}$. Following Breeden et al. [17], Table 4 presents coefficients after scaling to sum to one hundred percent.

The results in Table 4 support the connection between our productivity function in Equation (13) and marginal utility growth. Non-durable consumption is often used as a proxy for marginal utility growth in logutility or constant relative risk aversion settings. We note the coefficient for non-durables (asset 1 ) is significant at the $10 \%$ level. Similar to BGL1989, we find large coefficients on long term government bonds (asset 13) and low grade corporate bonds (asset 15). The correlation between the fitted mimicking portfolio and the original productivity time series is 0.45 , similar to the correlation of 0.57 between consumption growth and the associated factor mimicking portfolio of Breeden et al. [17].

The estimated coefficients from Equation (18) are combined with daily returns for the 16 assets listed in Table 4 to form a daily factor-mimicking portfolio time series:

$$
F M P_{t}=\sum_{i=1}^{16} \hat{\beta}_{i} R_{i t}
$$

As shown in Cochrane ([4], p. 109) FMP carries the same pricing information as $P R O D$. We use this newly formed daily productivity time series in the following unconditional and conditional regressions.

\subsection{Unconditional Asset Pricing Tests}

Regressions are performed using generalized methods of moments (GMM) with standard errors corrected for heteroskedasticity and autocorrelation [16]. Ferson and Foerster [18] find two stage GMM estimation in larger (greater than 60 time series observations) and complex systems (ten or more moment conditions) tends to over reject. In such systems the authors suggest the use of an iterated approach. Given the size (over 13,000 time series observations) and complexity (ten assets) of our study, we employ the iterated GMM approach following Ferson and Harvey [19] and Ferson and Foerster [18].

We perform the full sample unconditional regressions on the CAPM, Fama-French three-factor model (FF3FM), and the single factor productivity-based CAPM model (PCAPM) using our newly constructed factor mimicking portfolio time series $\left(F M P_{t}\right)$ :

$$
\begin{array}{cc}
E\left[R_{e i}-\alpha_{i}-\beta_{i} M R P_{t}\right]=0 & \text { CAPM } \\
E\left[R_{e i}-\alpha_{i}-\beta_{m i} M R P_{t}-\beta_{s i} S M B_{t}-\beta_{h i} H M L_{t}\right]=0 & \text { FF3FM } \\
E\left[R_{e i}-\alpha_{i}-\beta_{i} F M P_{t}\right]=0 & \text { PCAPM }
\end{array}
$$

We assess model fit by performing the $J$-test on a restricted regression $\left(\alpha_{i}=0\right)$ to test that the pricing errors (moment conditions) are jointly zero, $H_{0}: E\left[\mathbf{g}_{i}\right]=0 \forall i$. Larger $J$ values indicate larger pricing errors. Rejection of the null implies rejection of the model.

\subsection{Conditional Asset Pricing Tests}

As mentioned in the Introduction, coefficients for the CAPM and similar linear factor models are necessarily time-varying. Identifying specific macroeconomic variables that cause this time variance is difficult. Following 
Lewellen and Nagel [5] we perform short-window regressions to directly estimate the time series of coefficients without having to identify and incorporate specific macroeconomic variables. Quarterly coefficient estimation based on daily return data produces the most significant results in Lewellen and Nagel [5] and we repeat that approach here.

We perform the short-window regressions on the CAPM, the FF3FM, and the PCAPM:

$$
\begin{array}{cc}
R_{\text {eit }}=\alpha_{i t}+\beta_{i t} M R P_{t}+\epsilon_{i t} & \text { CAPM } \\
R_{\text {eit }}=\alpha_{i t}+\beta_{\text {mit }} M R P_{t}+\beta_{\text {sit }} S M B_{t}+\beta_{\text {hit }} H M L_{t}+\epsilon_{i t} & \text { FF3FM } \\
R_{\text {eit }}=\alpha_{i t}+\beta_{i t} F M P_{t}+\epsilon_{i t} & \text { PCAPM }
\end{array}
$$

Mean values of the alpha and beta time series are computed and significance is tested via $p$-values based on Andrews [16] heteroskedasticity and autocorrelation consistent (HAC) standard errors. In addition, we test that alphas are jointly zero, $H_{0}: \alpha_{i}=0 \forall i$, via the $\chi^{2}$ statistic. Robust errors are especially necessary in this setting since the estimated alphas and betas are likely to have significant autocorrelation.

\section{Results}

\subsection{Unconditional Estimations}

Results for the unconditional GMM estimation of Equations (20)-(22) are presented in Table 5. All three models, the CAPM, the FF3FM, and the PCAPM, are rejected by the $J$ test. This result is not surprising and is in fact predicted by Lin and Zhang [1]. However, there are several encouraging observations. First, we find that momentum portfolio returns are related to book-to-market (9 out of $10 \mathrm{HML}$ coefficients $\beta_{h i}$ are significant) and productivity (all FMP coefficients $\beta_{i}$ are significant). That observation is consistent with the investment and market return expression of Lin and Zhang [1], Equation (16). Second, the $J$ statistic is smaller for the PCAPM $(J=41.53)$ than both the CAPM $(J=52.38)$ and the FF3FM $(J=56.49)$. Finally, the spread between the long $(M 10)$ and short positions (M01) of the UMD portfolio is smaller for the PCAPM (0.0541) than both the CAPM (0.0643) and the FF3FM (0.0647). Note the significant alphas in Table 6 measure riskadjusted return while the returns in Table 3 are not risk-adjusted.

Table 5 reports results of unconditional GMM estimation of the CAPM, the Fama-French three-factor model (FF3FM), and the productivity-based CAPM (PCAPM) moment conditions $E[\mathbf{g}]=0$.

$$
\begin{aligned}
& E\left[R_{e i t}-\alpha_{i}-\beta_{i} M R P_{t}\right]=0 \quad \mathrm{CAPM} \\
& E\left[R_{\text {eit }}-\alpha_{i}-\beta_{m i} M R P_{t}-\beta_{s i} S M B_{t}-\beta_{h i} H M L_{t}\right]=0 \quad \text { FF3FM } \\
& E\left[R_{e i t}-\alpha_{i}-\beta_{i} F M P_{t}\right]=0 \quad \text { PCAPM }
\end{aligned}
$$

Estimations are performed using daily excess returns of the CRSP market value weighted portfolio (MRP), the Fama-French "size" portfolio ( $S M B)$, the Fama-French "distress" portfolio $(H M L)$, and ten prior return portfolios $\left(R_{e i}=M x x-R_{f}\right)$. The factor mimicking portfolio $(F M P)$ is estimated following the procedure of Section 3.4. Intercept values $\alpha_{i}$ are expressed in percentages. $p$-values for all estimates are in italics. $\chi^{2}$ statistics are provided for the test of $H_{0}: \alpha_{i}=0 \forall i$ in unrestricted regressions. $J$ statistics are provided for the test of $H_{0}: E\left[\mathbf{g}_{i}\right]=0 \forall i$ in restricted $\left(\alpha_{i}=0\right)$ regressions. Significance at the $5 \%$ level or better is indicated by bold estimates. All test statistics are based on Andrews [16] heteroskedasticity and autocorrelation consistent (HAC) covariance matrices. The sample includes daily data from 19620101 to 20121231.

\subsection{Conditional Estimations}

Table 6 presents results for the short-window regressions of Equations (23)-(25). Our results are consistent with Lewellen and Nagel [5]: the conditional CAPM does not explain momentum portfolio returns. We expand on their findings by noting that alphas are significant in both the conditional CAPM and the conditional FF3FM. On a positive note, 9 out of 10 alphas are insignificant for the conditional PCAPM. The $\chi^{2}$ value for the PCAPM model is higher than both the CAPM and the FF3FM models (129 for the PCAPM vs. 89.4 for the CAPM and 73.1 for the FF3FM). This is due largely to the highly significant $M 10$ alpha, consistent with the unconditional estimation. 
Table 5. Unconditional GMM estimation results.

\begin{tabular}{|c|c|c|c|c|c|c|c|c|}
\hline \multirow[b]{2}{*}{$i$} & \multicolumn{2}{|c|}{ CAPM } & \multicolumn{4}{|c|}{ FF3FM } & \multicolumn{2}{|c|}{ PCAPM } \\
\hline & $\alpha_{i}$ & $\beta_{i}$ & $\alpha_{i}$ & $\beta_{m i}$ & $\beta_{s i}$ & $\beta_{h i}$ & $\alpha_{i}$ & $\beta_{i}$ \\
\hline \multirow[t]{2}{*}{ M01 } & -0.0399 & 1.3136 & -0.0353 & 1.4220 & 0.4861 & 0.5000 & -0.0213 & 0.1546 \\
\hline & 0.0000 & 0.0000 & 0.0001 & 0.0000 & 0.0000 & 0.0000 & 0.1918 & 0.0003 \\
\hline \multirow[t]{2}{*}{ M02 } & -0.0139 & 1.1433 & -0.0131 & 1.2130 & 0.1494 & 0.4059 & 0.0015 & 0.1480 \\
\hline & 0.0315 & 0.0000 & 0.0370 & 0.0000 & 0.0000 & 0.0000 & 0.9063 & 0.0002 \\
\hline \multirow[t]{2}{*}{ M03 } & -0.0019 & 1.0203 & -0.0025 & 1.0705 & 0.0187 & 0.3382 & 0.0112 & 0.1424 \\
\hline & 0.7099 & 0.0000 & 0.5988 & 0.0000 & 0.5514 & 0.0000 & 0.3100 & 0.0000 \\
\hline \multirow[t]{2}{*}{ M04 } & -0.0007 & 0.9842 & -0.0019 & 1.0224 & -0.0353 & 0.2822 & 0.0105 & 0.1594 \\
\hline & 0.8668 & 0.0000 & 0.6268 & 0.0000 & 0.0862 & 0.0000 & 0.3039 & 0.0000 \\
\hline \multirow[t]{2}{*}{ M05 } & -0.0019 & 0.9469 & -0.0032 & 0.9789 & -0.0540 & 0.2489 & 0.0083 & 0.1624 \\
\hline & 0.5972 & 0.0000 & 0.3400 & 0.0000 & 0.0025 & 0.0000 & 0.3931 & 0.0000 \\
\hline \multirow[t]{2}{*}{ M06 } & 0.0029 & 0.9245 & 0.0015 & 0.9487 & -0.0677 & 0.2022 & 0.0114 & 0.1794 \\
\hline & 0.3673 & 0.0000 & 0.6268 & 0.0000 & 0.0009 & 0.0000 & 0.2273 & 0.0000 \\
\hline \multirow[t]{2}{*}{ M07 } & 0.0014 & 0.9172 & 0.0002 & 0.9325 & -0.0698 & 0.1422 & 0.0092 & 0.1894 \\
\hline & 0.6421 & 0.0000 & 0.9446 & 0.0000 & 0.0000 & 0.0000 & 0.3289 & 0.0000 \\
\hline \multirow[t]{2}{*}{ M08 } & 0.0132 & 0.9268 & 0.0120 & 0.9381 & -0.0682 & 0.1129 & 0.0201 & 0.2050 \\
\hline & 0.0002 & 0.0000 & 0.0005 & 0.0000 & 0.0004 & 0.0001 & 0.0339 & 0.0000 \\
\hline \multirow[t]{2}{*}{ M09 } & 0.0073 & 0.9775 & 0.0078 & 0.9808 & 0.0379 & 0.0039 & 0.0150 & 0.2101 \\
\hline & 0.0605 & 0.0000 & 0.0452 & 0.0000 & 0.0105 & 0.8827 & 0.1393 & 0.0000 \\
\hline \multirow[t]{2}{*}{ M10 } & 0.0244 & 1.1449 & 0.0294 & 1.1234 & 0.3415 & -0.3240 & 0.0328 & 0.2553 \\
\hline & 0.0001 & 0.0000 & 0.0000 & 0.0000 & 0.0000 & 0.0000 & 0.0101 & 0.0000 \\
\hline \multirow[t]{2}{*}{$J$} & \multicolumn{2}{|c|}{52.38} & \multicolumn{4}{|c|}{56.49} & \multicolumn{2}{|c|}{41.53} \\
\hline & \multicolumn{2}{|c|}{0.0000} & \multicolumn{4}{|c|}{0.0000} & \multicolumn{2}{|c|}{0.0000} \\
\hline
\end{tabular}

Table 6. Conditional estimation results.

\begin{tabular}{|c|c|c|c|c|c|c|c|c|}
\hline & \multicolumn{2}{|c|}{ CAPM } & \multicolumn{4}{|c|}{ FF3FM } & \multicolumn{2}{|c|}{ PCAPM } \\
\hline$i$ & $\alpha_{i}$ & $\beta_{i}$ & $\alpha_{i}$ & $\beta_{m i}$ & $\beta_{s i}$ & $\beta_{h i}$ & $\alpha_{i}$ & $\beta_{i}$ \\
\hline \multirow[t]{2}{*}{ M01 } & -0.0339 & 1.1647 & -0.0227 & 1.1900 & 0.4060 & 0.0815 & -0.0213 & -0.0204 \\
\hline & 0.0000 & 0.0000 & 0.0009 & 0.0000 & 0.0000 & 0.3773 & 0.115 & 0.795 \\
\hline \multirow[t]{2}{*}{ M02 } & -0.0114 & 1.0287 & -0.0028 & 1.0547 & 0.1174 & 0.1017 & -0.0001 & 0.0189 \\
\hline & 0.0336 & 0.0000 & 0.6435 & 0.0000 & 0.0073 & 0.0623 & 0.990 & 0.794 \\
\hline \multirow[t]{2}{*}{ M03 } & -0.0004 & 0.9533 & 0.0006 & 0.9840 & 0.0030 & 0.0951 & 0.0070 & 0.0484 \\
\hline & 0.8317 & 0.0000 & 0.8248 & 0.0000 & 0.9036 & 0.0170 & 0.415 & 0.493 \\
\hline \multirow[t]{2}{*}{ M04 } & 0.0000 & 0.9280 & 0.0036 & 0.9624 & -0.0263 & 0.0963 & 0.0074 & 0.0661 \\
\hline & 0.9847 & 0.0000 & 0.2880 & 0.0000 & 0.1719 & 0.0067 & 0.297 & 0.349 \\
\hline \multirow[t]{2}{*}{ M05 } & -0.0015 & 0.9093 & -0.0010 & 0.9387 & -0.0316 & 0.0774 & 0.0041 & 0.0690 \\
\hline & 0.5717 & 0.0000 & 0.7123 & 0.0000 & 0.1226 & 0.0112 & 0.538 & 0.354 \\
\hline \multirow[t]{2}{*}{ M06 } & 0.0021 & 0.9145 & 0.0016 & 0.9466 & -0.0167 & 0.0971 & 0.0065 & 0.0864 \\
\hline & 0.3123 & 0.0000 & 0.5835 & 0.0000 & 0.3415 & 0.0035 & 0.345 & 0.253 \\
\hline \multirow[t]{2}{*}{ M07 } & 0.0007 & 0.9431 & -0.0021 & 0.9685 & -0.0121 & 0.0884 & 0.0047 & 0.0965 \\
\hline & 0.7575 & 0.0000 & 0.4677 & 0.0000 & 0.5555 & 0.0074 & 0.564 & 0.216 \\
\hline \multirow[t]{2}{*}{ M08 } & 0.0105 & 0.9884 & 0.0090 & 1.0048 & -0.0133 & 0.0852 & 0.0156 & 0.1009 \\
\hline & 0.0000 & 0.0000 & 0.0019 & 0.0000 & 0.6551 & 0.0194 & 0.053 & 0.214 \\
\hline \multirow[t]{2}{*}{ M00 } & 0.0054 & 1.0626 & 0.0011 & 1.0655 & 0.0708 & 0.0244 & 0.0105 & 0.0903 \\
\hline & 0.1160 & 0.0000 & 0.7715 & 0.0000 & 0.0570 & 0.6171 & 0.272 & 0.281 \\
\hline \multirow[t]{2}{*}{ M10 } & 0.0247 & 1.2695 & 0.0210 & 1.2226 & 0.3450 & -0.1465 & 0.0334 & 0.0193 \\
\hline & 0.0000 & 0.0000 & 0.0000 & 0.0000 & 0.0000 & 0.1247 & 0.006 & 0.850 \\
\hline \multirow[t]{2}{*}{$\chi^{2}$} & \multicolumn{2}{|c|}{89.4} & \multicolumn{4}{|c|}{73.1} & \multicolumn{2}{|c|}{129} \\
\hline & \multicolumn{2}{|c|}{0.0000} & \multicolumn{4}{|c|}{0.0000} & \multicolumn{2}{|c|}{0.0000} \\
\hline
\end{tabular}


Another interesting observation is that all PCAPM betas are insignificant in contrast to significant CAPM betas. Lewellen and Nagel [5] note the CAPM betas do not vary enough to explain anomalies. Although the PCAPM is rejected by the $\chi^{2}$ statistic, the insignificant conditional betas suggest the PCAPM betas vary more than the CAPM betas. Also, we find the HML extreme portfolio betas $\beta_{h i}$ are insignificant in the conditional estimation. Again, the FF3FM is rejected but we have evidence that time variance in market-to-book ratios loadings is greater than that of traditional CAPM betas.

Table 6 reports mean conditional alphas and betas of the CAPM, Fama-French three-factor model (FF3FM), and the productivity-based CAPM (PCAPM) applied to ten prior return portfolios.

$$
\begin{array}{ccc}
R_{e i t}=\alpha_{i t}+\beta_{i t} M R P_{t}+\epsilon_{i t} & \text { CAPM } & \\
R_{e i t}=\alpha_{i t}+ & \beta_{\text {mit }} M R P_{t}+\beta_{s i} S M B_{t}+\beta_{h i} H M L_{t}+\epsilon_{i t} & \text { FF3FM } \\
R_{e i t}=\alpha_{i t}+\beta_{i t} \text { FMP }_{t}+\epsilon_{i t} \quad \text { PCAPM } &
\end{array}
$$

Rolling alphas $\left(\alpha_{i t}\right)$ and betas $\left(\beta_{i t}\right)$ are estimated every 60 trading days (quarterly) using daily excess returns of the CRSP market value weighted portfolio (MRP), the Fama-French "size" portfolio (SMB), the Fama-French "distress" portfolio $(H M L)$, and ten prior return portfolios $\left(R_{e i}=M x x-R_{f}\right)$. The factor mimicking portfolio (FMP) is estimated following the procedure of Section 3.4. Intercept values $\alpha_{i}$ are expressed in percentages. $\chi^{2}$ statistics are provided for the test of $H_{0}: \alpha_{i}=0 \forall i$. $p$-values for all estimates are in italics. Significance at the $5 \%$ level or better is indicated by bold estimates. All test statistics are based on Andrews [16] heteroskedasticity and autocorrelation consistent (HAC) covariance matrices. The sample includes daily data from 19620101 to 20121231.

\section{Conclusions}

We find that momentum portfolio returns are still unexplainable after addressing two major concerns in the "Investment Manifesto" of Lin and Zhang [1]: lack of economic basis in risk factor models and aggregate data measurement error. Our model represents a synthesis of the exchange economy model of Lucas and closed economy exogenous growth model of King and Rebelo. We mitigate data measurement error by utilizing firmlevel financial data and production functions rather than macroeconomic data and utility functions. Although our results fail to explain momentum, they are consistent with the "Investment Manifesto" suggestion that firm-level market-to-book and productivity are important factors in describing returns.

Specifically, we find evidence in support of the significance of productivity and market-to-book in pricing momentum portfolios. We observe significant productivity betas in unconditional estimations and $J$ values that are lower in our productivity-based CAPM than both the traditional CAPM and Fama-French three-factor models. Second, in conditional estimations, we find that loadings on our productivity factor-mimicking portfolio vary more than those on the market risk premium of the CAPM. Turning to market-to-book, we find significant loadings on the market-to-book factor in the Fama-French three-factor model unconditional estimation.

In sum, we document productivity and market-to-book ratios are related to momentum portfolio returns at the aggregate level. Future research that incorporates firm-level market-to-book and productivity may move the literature closer to a more complete explanation of momentum portfolio returns and anomalies in general.

\section{Acknowledgements}

Earlier versions of this paper were presented at the 2010 Oxford Business and Economics Conference, Pepperdine University, The University of Memphis, and The University of Tennessee. The authors would like to thank participants of those presentations for their constructive comments. We would also like to thank Wayne Ferson for helpful comments and suggested readings relevant to this paper and James Kuhle for editorial suggestions.

\section{References}

[1] Lin, X.J. and Zhang, L. (2013) The Investment Manifesto. Journal of Monetary Economics, 60, 351-366. http://dx.doi.org/10.1016/j.jmoneco.2013.01.001

[2] Carhart, M.M. (1997) On Persistence in Mutual Fund Performance. The Journal of Finance, 52, 57-82.

[3] Fama, E.F. and French, K.R. (1996) Multifactor Explanations of Asset Pricing Anomalies. The Journal of Finance, 51, 
55-84. http://dx.doi.org/10.1111/j.1540-6261.1996.tb05202.x

[4] Cochrane, J.H. (2005) Asset Pricing. Princeton University Press, Princeton.

[5] Lewellen, J. and Nagel, S. (2006) The Conditional CAPM Does Not Explain Asset-Pricing Anomalies. Journal of Financial Economics, 82, 289-314. http://dx.doi.org/10.1016/j.jfineco.2005.05.012

[6] King, R.G. and Rebelo, S.T. (1999) Resuscitating Real Business Cycles. In: Taylor, J.B. and Woodford, M., Eds., Handb Macroecon, North Holland, Amsterdam.

[7] Lucas Jr., R.E. (1978) Asset Prices in an Exchange Economy. Econometrica, 46, 1426-1445. http://dx.doi.org/10.2307/1913837

[8] Abel, A.B. and Blanchard, O.J. (1983) An Intertemporal Model of Saving and Investment. Econometrica, 51, 675-692. http://dx.doi.org/10.2307/1912153

[9] Sala-i Martin, X. (1990) Lecture Notes on Economic Growth (i): Introduction to the Literature and Neoclassical Models. NBER Work Paper Series, Work Paper 3563.

[10] Jorgenson, D.W. (1972) Investment Behavior and the Production Function. Bell Journal of Economics, 3, 220-251. http://dx.doi.org/10.2307/3003076

[11] Hayashi, F. (1982) Tobin's Marginal q and Average q: A Neoclassical Interpretation. Econometrica, 50, 213-224. http://dx.doi.org/10.2307/1912538

[12] Arroyo, C.R. (1996) Testing a Production-Based Asset-Pricing Model. Economic Inquiry, 357-377.

[13] Brock, W.A. (1982) Asset Prices in a Production Economy, In: The Economics of Information and Uncertainty, Chapter 1. The University of Chicago Press, Chicago, 1-46.

[14] Fama, E.F. and French, K.R. (2012) Size, Value, and Momentum in International Stock Returns. Journal of Financial Economics, 105, 457-472. http://dx.doi.org/10.1016/j.jfineco.2012.05.011

[15] Chordia, T. and Shivakumar, L. (2006) Earnings and Price Momentum. Journal of Financial Economics, 80, 627-656. http://dx.doi.org/10.1016/j.jfineco.2005.05.005

[16] Andrews, D.W.K. (1991) Heteroskedasticity and Autocorrelation Consistent Covariance Matrix Estimation. Econometrica, 59, 817-858. http://dx.doi.org/10.2307/2938229

[17] Breeden, D.T., Gibbons, M.R. and Litzenberger, R.H. (1989) Empirical Tests of the Consumption-Oriented CAPM. The Journal of Finance, 44, 231-262.

[18] Ferson, W.E. and Foerster, S.R. (1994) Finite Sample Properties of the Generalized Method of Moments in Tests of Conditional Asset Pricing Models. Journal of Financial Economics, 36, 29-55. http://dx.doi.org/10.1016/0304-405X(94)90029-9

[19] Ferson, W.E. and Harvey, C.R. (1992) Seasonality and Consumption-Based Asset Pricing. The Journal of Finance, 47, 511-552. http://dx.doi.org/10.1111/j.1540-6261.1992.tb04400.x 